\title{
Reseña de Geomorfología litoral de Menorca. Dinámica, Evolución y Prácticas de Gestión
}

\author{
Review of Geomorfología litoral de Menorca. Dinámica, \\ Evolución y Prácticas de Gestión
}

Pablo Fraile-Jurado ${ }^{1}$ if

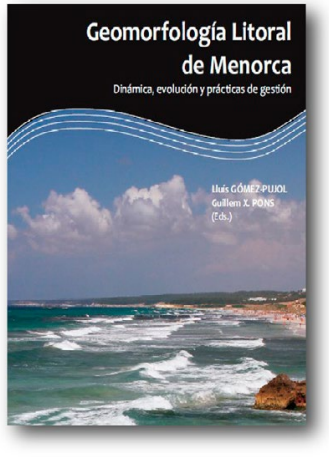

แกเก

Editores: Gómez-Pujol, L. y Pons, G. X.

Título: Geomorfología litoral de Menorca. Dinámica, Evolución y Prácticas de Gestión Año: 2017

Ciudad: Palma de Mallorca, Islas Baleares

Editorial: Societat d'Història Natural de les Balears

Páginas: 296pp.

ISBN: 978-84-697-5311-8
Difícilmente puede pasarle por alto al visitante de Menorca una isla que de norte a sur apenas alcanza los $20 \mathrm{~km}$ de ancho, y donde la influencia del mar condiciona y matiza todos los aspectos del medio físico, de la vida y de la cultura. Es precisamente este tema, el litoral, en todos sus aspectos, que representa el hilo conductor del libro Geomorfología litoral de Menorca. Dinámica, Evolución y Prácticas de Gestión, en el que 30 autores participan en esta publicación sobre el litoral de Menorca coordinada por la Sociedad de Historia Natural de las Baleares. Se trata de una monografía que se presentó aprovechando la celebración de las IX Jornadas de Geomorfología Litoral, celebradas en la isla de Menorca (Maó, 13 al 15 de septiembre de 2017). Las Jornadas se convirtieron en un buen marco para la edición de un libro que pasara revista a la geomorfología litoral menorquina y complementara otras dos monografías ya existentes sobre la Geografía Física de Menorca y la Historia Natural de la mitad meridional de la isla, que durante los últimos veinte años ha sido el escenario de numerosas campañas y proyectos de investigación. De esta manera se pone al alcance de los especialistas, así como del público en general, las líneas de trabajo y los avances que, especialmente durante el último lustro, se han desarrollado en el marco de la isla de Menorca. Además, y dentro del ámbito académico de las Jornadas de Geomorfología Litoral, supone la continuación lógica del libro editado en 2007 Geomorfología Litoral. Migjorn y Llevant de Mallorca por J.J. Fornós, J. Ginés y L. Gómez-Pujol en 2007, distribuido igualmente en el contexto de las Jornadas celebradas en Palma de Mallorca en dicho año.

El presente volumen cuenta con diez artículos relacionados con el litoral y cuatro itinerarios, articulándose en dos partes. Se encuentra editado a color y en general mantiene un apartado gráfico de gran calidad, tanto debido a la calidad de la impresión como al cuidado puesto por los autores en mantener un elevado nivel gráfico. En una primera parte se aborda capítulo a capítulo el estado de la cuestión de diversos aspectos del litoral de Menorca, desde su extensión y tipología, a los procesos y dinámica de acantilados y playas, el transporte eólico y los sistemas dunares o, ya en el campo de los estudios evolutivos, la existencia de mantos eólicos holocenos, el registro fósil litoral cuaternario de la isla y la presencia de campos de bloques o bloques aislados en las costas rocosas. No podía faltar, por haberse convertido en un referente y desde la me-

1 Departamento de Geografía física y A.G.R. Universidad de Sevilla, España. pfraile@us.es 
nor de la Gimnesias haberse exportado más allá, un capítulo que explicitara y resumiera el amplio bagaje de lo que se ha venido a conocer como el modelo 'Menorca' de gestión litoral. La segunda parte consiste en cuatro itinerarios científicos que pretenden acercar al lector hasta localidades en las que pueda apreciar con detalle los temas abordados en la primera parte del libro, así como conocer los resultados de las actividades de investigación más recientes desarrolladas en la isla de Menorca y que se han materializado en diversas tesis doctorales centradas en la geomorfología litoral. El libro pone de manifiesto un aspecto no siempre habitual en la comunidad científica: la transversalidad y la colaboración entre diferentes grupos de investigación y/o profesionales y aficionados para contribuir al avance del conocimiento del litoral. No debería pasar desapercibida la nómina de geógrafos, geólogos, oceanógrafos, biólogos, arqueólogos, historiadores y otros diletantes que bien desde la Universidad, centros de investigación o bien desde consultorías ambientales, consultorías en arqueología u organizaciones no gubernamentales, han participado en la presente monografía o que en la actualidad y a la espera de futuros resultados están trabajando en el marco de las costas menorquinas.

El libro Geomorfología litoral de Menorca. Dinámica, Evolución y Prácticas de Gestión, disponible en formato pfd, permite una amplia visión de aspectos litorales, tanto naturales como históricos de la isla, convirtiéndose en un amplio compendio de trabajos científicos, algunos de ellos aplicados y otros a tener presentes en el estudio de los sistemas litorales del Mediterráneo como referentes o bien como comparativas. Este volumen, junto a otros relacionados con la biología, ecología, geología y geomorfología de las islas Baleares, puede ser descargado en formato pdf en el siguiente enlace: http://www.shnb.org/SHN monografies.html.

La obra abarca un amplio abanico de temas litorales desde el trabajo de Balaguer et al. referente al marco físico del litoral de Menorca, que recopila todos los datos actualizados sobre aspectos fisiográficos y los diferentes tipos de costa de la isla y que a la vez representa un excelente documento inventario útil para la planificación y gestión. En un estudio más profundo realizado por Fornós et al. se analiza la costa rocosa del Migjorn de Menorca, haciendo incidencia en la formación de las calas y barrancos, la morfologías de acantilados y la influencia tectónica. Roig-Munar et al. tratan la morfometría de bloques de tsunamis en las costas rocosas de la isla, basado en una tesis doctoral recientemente defendida sobre la presencia de bloques en el conjunto del archipiélago balear, y que son atribuidos a las trayectorias de tsunamis del $\mathrm{N}$ de Argelia, tema relacionado con los riesgos geológicos a los que se enfrentan las costas de las Baleares. Destacan los trabajos sobre playas, realizado por Gómez-Pujol et al., y sobre dunas, realizado por Pons et al. Ambos trabajos elaboran una clasificación, distribución y morfología de estos sistemas litorales, convirtiéndose en dos estudios válidos para los gestores como herramienta de planificación y gestión. Estos dos trabajos enumeran y clasifican las playas de Menorca, 114 sistemas, y los sistemas dunares, 28 sistemas, aunque Balaguer et al. describen 35 sistemas dunares en esta misma monografía. Los trabajos de Pomar et al. sobre las eolianitas de Menorca, y que son la base de su tesis doctoral, ponen de manifiesto toda una serie de morfologías dunares adosadas a los acantilados que ejemplifican antiguos niveles marinos así como los paleoambientes que las formaron en períodos más cálidos que dieron lugar a depósitos coluviales y aluviales. El registro fósil de los depósitos cuaternarios es tratado por Vicens y Pons, inventariando su registro paleontológico con altos grados de taxones terrestres y elevados endemismos. En esta misma línea se presentan los resultados de un extenso estudio focalizado en la costa rocosa del Norte de la isla, realizado por Martín-Prieto et al., donde se estudian diferentes morfologías dunares desvinculadas de la línea de costa, denominados mantos eólicos, y que permiten toda una serie de hipótesis sobre su morfología, morfometría y distribución, así como los cambios de nivel del mar, tectónicos y paleoclimáticos. La actividad humana en el litoral queda registrada mediante numerosos yacimientos arqueológicos ubicados en las costas rocosas y relacionado con los datos existentes sobre el aprovechamiento de los recursos costeros durante más de 2000 años (2300-123 a.C.). Este estudio, realizado por Anglada et al., muestra la distribución y estudio de diferentes yacimientos a lo largo del perímetro litoral. La gestión litoral, basada en aspectos geomorfógicos, queda recopilada en un capítulo donde realizado por Roig-Munar et al. en que se exponen las medidas de gestión y recuperación que evitan la degradación e implican la recuperación de las morfologías playa-duna. Este capítulo valora la evolución espacio-temporal de los sistemas dunares basándose en variables geomorfológicas y de gestión. Algunos de estos diez capítulos realizados por consultores profesionales pone de manifiesto que la investigación no siempre se encuentra asociada a centros académicos, sin que este hecho repercuta en la calidad y rigor de los trabajos. 
Como capítulos finales encontramos cuatro itinerarios sobre estudios realizados in situ y que pueden ser visitados con la ayuda de este libro, como son: la diagnosis geomorfológica y gestión aplicada en un sector de la costa $\mathrm{N}$ que estaba sometido a una fuerte presión que desencadenó procesos erosivos. Un estudio sobre la dinámica eólica en el sistema dunar de Tirant, $\mathrm{N}$ de Menorca. La visita de un itinerario por la costa rocosa del SE de Menorca para observar bloques de tsunami y los efectos del tsunami acaecido el 23 de mayo de 2013, y la visita de diferentes calas y acantilados del Migjorn de Menorca. Estos 4 itinerarios podrían perfectamente encontrarse en una guía de itinerarios geológicos y geomorfológicos de la isla.
El libro Geomorfología litoral de Menorca. Dinámica, Evolución y Prácticas de Gestión se convierte pues en un documento aplicado imprescindible para la formación en el estudio costero del Mediterráneo occidental, resultando un reflejo del estado actual de los estudios costeros en Baleares realizados por algunos investigadoress. Este monográfico sobre Menorca contribuye en sí mismo a ser el referente sobre el estado de la cuestión de la geomorfología litoral de la isla, y supone un estímulo para posteriores investigaciones, así como incentiva la visita y conocimiento de las localidades que en él se estudian. 